\title{
Fixing the conformation of calix[4]arenes: When are three carbons not enough?
}

\author{
Susan E. Matthews ${ }^{\star[a]}$, Samy Cecioni ${ }^{[b]}$, John E. O'Brien ${ }^{[c]}$, Colin J MacDonald ${ }^{[d]}$, David L. Hughes ${ }^{[d]}$, \\ Garth A. Jones ${ }^{[\mathrm{d}]}$, Stephen H. Ashworth ${ }^{[\mathrm{d}]}$ and Sébastien Vidal ${ }^{[\mathrm{b}]}$
}

\begin{abstract}
Calix[4]arenes are unique macrocycles that through judicious functionalisation at the lower-rim can be either fixed in one of four conformations or remain conformationally flexible. Introduction of propynyl or propenyl groups unexpectedly provides a new possibility; a unidirectional conformational switch, with the 1,3alternate and 1,2-alternate conformers switching to the partial cone conformation, whilst the cone conformation is unchanged, under standard experimental conditions. Using ${ }^{1} \mathrm{H}$ NMR kinetic studies, rates of switching have been shown to be dependent on the starting conformation, upper-rim substituent, where reduction in bulk enables faster switching, solvent and temperature with 1,2-alternate conformations switching fastest. $A b$ initio calculations (DFT) confirmed the relative stabilities of the conformations and point towards the partial cone conformer being the most stable of the four. The potential impact on synthesis through the 'click' reaction has been investigated and found not to be significant.
\end{abstract}

\section{Introduction}

Calix[4]arenes ${ }^{1-3}$ have proved to be one of the most versatile macrocyclic platforms available and have been exploited for a myriad of different applications in the fields of materials and biological chemistry including sensing, catalysis, medicinal chemistry and drug delivery. ${ }^{4} \mathrm{~A}$ particular advantage of the calix[4]arene skeleton, unlike larger analogues, is the ability to fix the macrocycle into one of four distinct conformations; cone, partial cone, 1,3-alternate or 1,2-alternate, by alkylation at the phenolic positions. ${ }^{1}$ Whilst this property has been extensively exploited in the design of rigid systems for directed topological interactions, ${ }^{1-4}$ less attention has been paid to harnessing

\footnotetext{
[a] Dr SE Matthews*

School of Pharmacy, University of East Anglia, Norwich

Research Park, Norwich, NR4 7TJ, UK

E-mail: susan.matthews@uea.ac.uk

[b] Dr S Cecioni, Dr S Vidal

Institut de Chimie et Biochimie Moléculaires et

Supramoléculaires, CO2-Glyco, UMR 5246, CNRS,

Université Claude Bernard Lyon 1, 43 Boulevard du 11

Novembre 1918, F-69622, Villeurbanne, France

[c] Dr JE O'Brien

School of Chemistry, University of Dublin, Trinity College,

Dublin 2, Ireland

[d] Dr CJ McDonald, Dr DL Hughes, Dr GA Jones, Dr SH Ashworth

School of Chemistry, University of East Anglia, Norwich

Research Park, Norwich, NR4 7TJ, UK
}

conformationally flexible derivatives which offer potential in the design of switchable and stimulus responsive materials.

Two general categories of switches have been observed in the calixarene family; those which alter the macrocycle state from one extreme variant of a conformation to another extreme variant of the same conformation and, more limitedly, a true switch between two conformational isomers of the macrocycle. Examples of the first include: vase to kite switching ${ }^{5}$ of extended resorcin[4]arene cavitands where a variety of stimuli such as reduction in temperature ${ }^{6}$ or $\mathrm{pH}^{7}$ redox $^{8}$ and metal cation ${ }^{9}$ complexation facilitate the switch or calix[4]tubes ${ }^{10}$ where complexation of potassium in the tube results in a change from flattened (or pinched) cone to cone conformations of the gating calix[4]arenes.

The most established examples of the second type are found with the calix[4]pyrroles ${ }^{11}$ where complexation of Lewis basic anions or variation in $\mathrm{pH}$ result in a reversible change from the stable 1,3-alternate to the cone conformation driven by hydrogen bond formation. This phenomenon has been exploited in the design of self-assembled cages and capsules $^{12}$ and responsive polymers, ${ }^{13}$ indicator displacement assays ${ }^{14}$ and logic gates. ${ }^{15}$

It is well established that introduction of propyl groups at the phenolic positions of calix[4]arenes is sufficient to lock $^{16,17}$ the individual conformations in place by blocking interconversion via ring inversion through the annulus. Accordingly heating of any of the conformations at $147{ }^{\circ} \mathrm{C}$ in 1,1,2,2-tetrachlorethane for 12 hours does not result in interconversion (Figure 1).

In contrast, calix[4]arenes bearing methyl groups are fully flexible ${ }^{16-21}$ and freely rotate between the four conformations with the equilibrium being solvent and $p$-substituent dependent (Figure 1). ${ }^{22,23}$ Both experimental NMR studies and MM3 calculations gave the relative stabilities for t-butyl calix[4]arene as partial cone $>$ cone $>1,2$-alternate $>1,3$-alternate ${ }^{21}$ at room temperature with the majority product at $-30{ }^{\circ} \mathrm{C}$ being assignable to the partial cone ${ }^{19,20}$

For calix[4]arenes functionalised with ethyl groups (Figure 1), a more complex situation results in which interconversion only occurs at elevated temperatures ${ }^{17,19,20}$ Heating of a mixture of cone, partial cone and 1,3-alternate conformers for 2 hours in 1,1,2,2-tetrachloroethane results in a mixture of all four conformers, with the 1,2-alternate conformation being the most abundant, ${ }^{16.17}$ whereas heating at lower temperatures in refluxing THF does not allow access to other conformers. ${ }^{20}$ 
With acetoxy substituents, interconversion of the cone conformer is observed on heating at $150{ }^{\circ} \mathrm{C}$ to give, after 384 hours, predominantly the 1,2-alternate and 1,3-alternate conformations with a relative stability of 1,3-alternate $>1,2$ alternate $>$ partial cone $>$ cone (Figure 1 ). In this case, steric repulsion between the larger acetoxy groups was proposed to direct the conformer distribution away from the cone. ${ }^{24}$ More recent studies on cyanomethoxy derivatives of both $t$-butyl calix[4]arene ${ }^{25}$ and calix[4]arene ${ }^{26}$ demonstrated that the partial cone and cone conformations were conformationally mobile, and that a thermodynamic equilibrium, with a biased distribution to the partial cone, could be achieved by heating either conformer. Interestingly, there was no evidence for rotation to either of the two alternate conformations

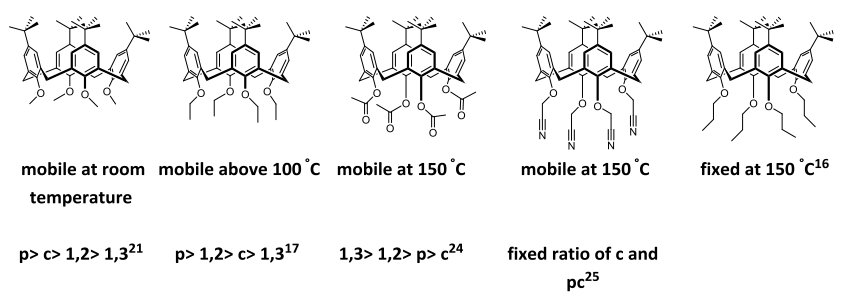

Figure 1. Summary of conformational flexibility of calixarenes ( $c=c o n e, p=$ partial cone, 1,2 = 1,2-alternate and 1,3 =1,3-alternate)

Stabilisation of a single conformation in equilibrium mixtures is possible through cation complexation, thus flexible tetramethoxycalix[4]arenes can be 'fixed' in the cone conformation by complexation with small cations such as $\mathrm{Li}^{+}$and $\mathrm{Na}^{+} .{ }^{27}$ Whereas conformationally flexible calix[4]arenes bridged at the lower rim by a crown ether moiety ${ }^{28}$ can switch from a mixture in which the majority conformation is the cone to a 1,3-alternate conformation through binding of a cesium cation within the crown. Recently, Neri29 demonstrated that switching to a single conformation can be achieved through guest inclusion by functionalisation at the upper-rim. Thus for a methoxycalix[4]arene derivatised with two carboxylate groups an equilibrium mixture favouring the partial cone was switched entirely to the cone by inclusion of a dicationic paraquat guest and reversed by changing the $\mathrm{pH}$.

Here, we investigated the conformational stability of tetrapropynyl calix[4]arenes and we report the first series of stimuli-responsive calixarene switches based on simple functionalisation of the lower rim. Through ${ }^{1} \mathrm{H}$ NMR, kinetic studies and ab initio calculations we demonstrate their tunability, response to two stimuli; temperature and solvent, and their unexpected ability to switch conformation in the solid state.

\section{Results and Discussion}

Whilst undertaking research on the widely used 1,3-alternate tetrapropynyl calix[4]arene $\mathbf{1}_{\mathbf{1}, \mathbf{3}}$ we were surprised to observe that upon heating in toluene overnight the material was entirely converted into the partial cone conformer $\mathbf{1}_{\mathbf{p}}$.
This prompted us to investigate the relative stabilities of the four different conformations (Figure 2) of tetrapropynyl calix[4]arene 1 and the ease of switching between conformations.

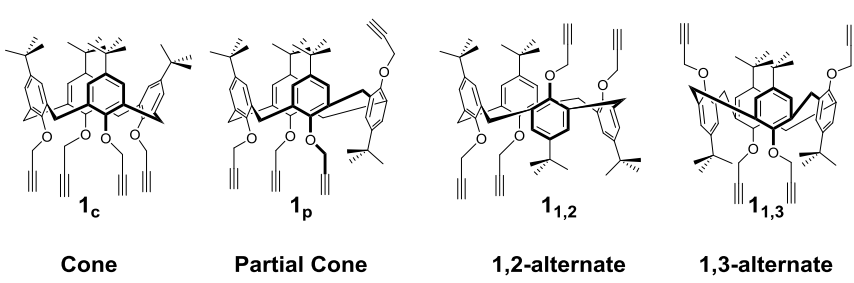

Figure 2. The four possible conformations of tetrapropynyl tetra-t-butyl calix[4]arene

Synthesis: The cone conformation $\mathbf{1}_{\mathbf{c}}$ was prepared following published procedures ${ }^{30}$ and $\mathbf{1}_{\mathrm{p}}$ and $\mathbf{1}_{\mathbf{1}, 3}$ were prepared in a single reaction, from the 1,3 -disubstituted calix[4]arene $\mathbf{2}$, as previously reported by us (Scheme 1 ). ${ }^{31}$ Single crystals of X-ray quality of $\mathbf{1}_{\mathbf{p}}$ were grown by slow evaporation from dichloromethane/ methanol (Figure S40). The crystal structure analysis confirmed that the molecule exhibited a classic partial cone conformation with a similar core conformation to that found previously, ${ }^{32}$ but with some of the propynyl groups in quite different orientations. Similar synthetic routes were employed for the synthesis of propynyl partial cone $\mathbf{5}_{\mathrm{p}}, \mathbf{6}_{\mathrm{p}}$ and 1,3-alternate $\mathbf{5}_{\mathbf{1 , 3}}, \mathbf{6}_{\mathbf{1}, 3}{ }^{33}$ conformations of $t$ octyl calix[4]arene and calix[4]arene respectively. Additionally the partial cone $\mathbf{7 p}^{34}$ and the 1,3-alternate $\mathbf{7 1 , 3}^{35}$ conformations of the tetrapropenyl calix[4]arene, for comparison, were prepared as previously reported.
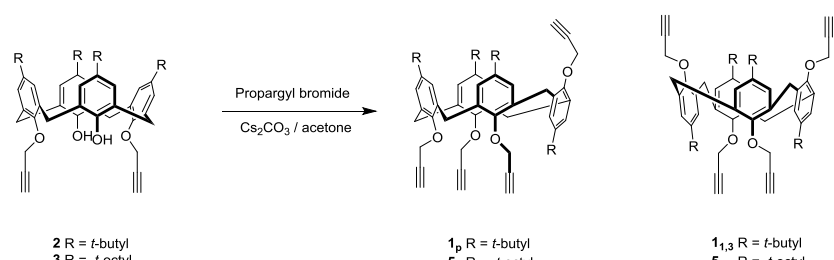

$\begin{aligned} 2 R & =t \text {-butyl } \\ 3 R & =t \text {-octyl } \\ 4 R & =H\end{aligned}$

$1_{\mathrm{p}} R=t$-butyl
$5_{\mathrm{p}} R=t$-octyl $5_{\mathrm{p}} \mathrm{R}=t$-octy
$\mathbf{6}_{\mathrm{p}} \mathrm{R}=\mathrm{H}$ $1_{1,3} R=t$-buty
$5_{1,3} R=t$-octy
$6_{1,3} R=H$
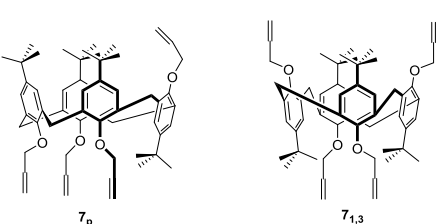

Scheme 1. Synthesis of 1,3-alternate and partial cone conformations

The 1,2-alternate conformation was accessed through the 1,2dialkyne 8 which was prepared, in acceptable yield, by the treatment of $t$-butyl calix[4]arene with a stoichiometric amount of propargyl bromide in the presence of sodium hydride (Scheme 2). ${ }^{36}$ Following the route of Lhoták et al., ${ }^{37}$ the 1,2-alternate conformer $\mathbf{1}_{\mathbf{1}, \mathbf{2}}$ was synthesized using potassium trimethylsilanolate as base in THF. Unlike the published procedure the reaction was terminated after 48 hours to maximise the yield of the desired conformation and minimise conversion to the partial cone conformer $\mathbf{1}_{\mathbf{p}}$ (vide infra). Formation of the 1,2alternate conformation was confirmed through ${ }^{1} \mathrm{H}$ NMR where the 
characteristic three signals (doublet, singlet, doublet) ${ }^{3}$ for the methylene bridge protons associated with $C_{2 h}$ symmetry were observed (Figure 3d). The analogous calix[4]arene $\mathbf{6}_{1,2}$ was prepared in a similar two-step process, albeit in low yield.
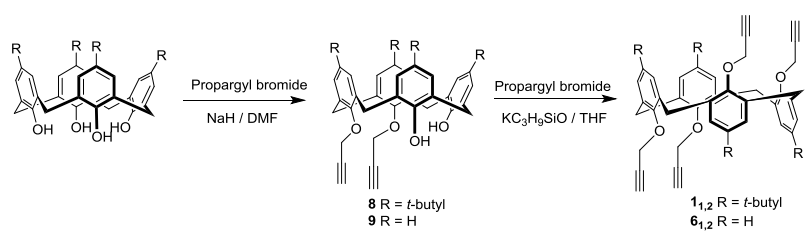

Scheme 2. Synthesis of 1,2-alternate conformations
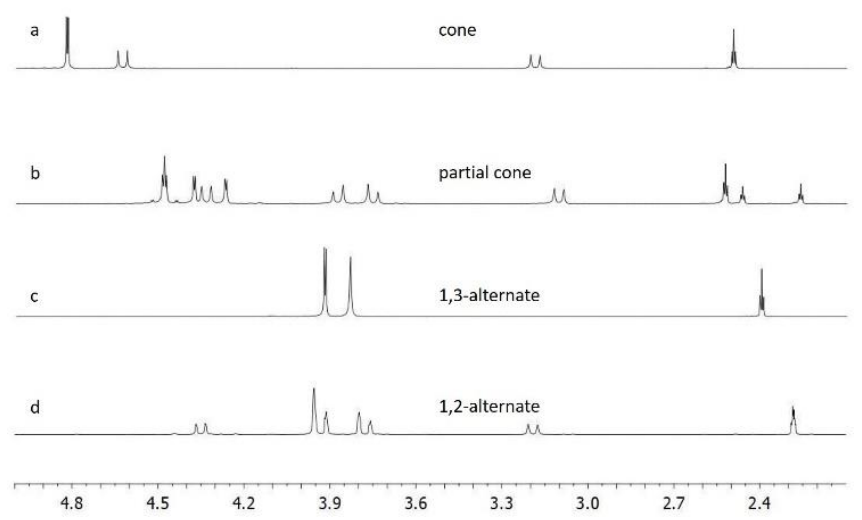

Figure 3. Partial ${ }^{1} \mathrm{H} \mathrm{NMR}\left(\mathrm{CDCl}_{3}\right)$ showing methylene and propynyl regions of a) $\mathbf{1}_{c}$, b) $\mathbf{1}_{p}$, c) $\mathbf{1}_{1,3}$, d) $\mathbf{1}_{1,2}$.

X-ray structure of $\mathbf{1}_{1,2}$ : Slow evaporation from a dichloromethane I hexane solution yielded single crystals of $\mathbf{1}_{\mathbf{1}, 2}$ suitable for $\mathrm{X}$-ray analysis (Figures 4 and S41-43). There are two independent calix[4]arene molecules in the crystal, one with $2 / m$ symmetry, centred at $(1 / 2,1 / 2,1 / 2)$; the second is centrosymmetric, about $(1,1 / 2$, $1 / 2$ ) and is disordered, lying over its mirror-image. The calix[4]arene rings in the two molecules have very similar shapes with the phenyl rings tilted similarly $\left(\mathrm{ca}_{70}^{\circ}\right)$ from the calix[4]arene ring mean-plane. The major differences between the two molecules are in the directions of the $\mathrm{O}-\mathrm{CH}_{2}$ bonds from the phenolic oxygen atoms. Cone-shaped cavities are not formed in 1,2-alternate calix[4]arenes.
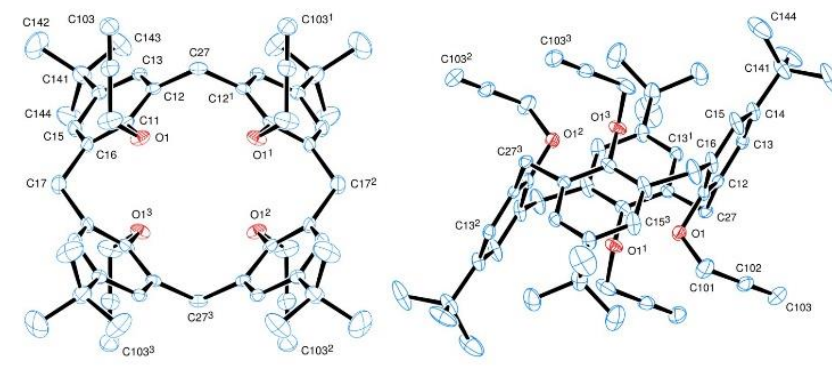

Figure 4. Views of the fully ordered calix[4]arene $\mathbf{1}_{\mathbf{1}, 2}$. Hydrogen atoms have been omitted for clarity. Thermal ellipsoids are drawn at the $30 \%$ probability level
Kinetic Studies: Initial studies focused on the stability of the four conformations of $\mathrm{p}$-t-butyl calix[4]arene tetraalkyne in toluene- $d_{8}$. Heating of the conformers at $80^{\circ} \mathrm{C}$ indicated that in the case of the 1,3-alternate conformer $\mathbf{1}_{\mathbf{1}, 3}$ and the 1,2-alternate conformer $\mathbf{1}_{1,2}$ almost complete conversion to the partial cone conformer $\mathbf{2}$ was achieved within four hours with no evidence of any other conformers present. In contrast, both the cone and the partial cone conformers $\mathbf{1}_{\mathrm{c}}$ and $\mathbf{1}_{\mathrm{p}}$ showed no conformational change under the same conditions (Figures S11, S12).

A full ${ }^{1} \mathrm{H}$ NMR kinetic study was then undertaken on $\mathbf{1}_{\mathbf{1 , 2}}$ and $\mathbf{1}_{1,3}$. Samples were heated for 3 hours at $5^{\circ} \mathrm{C}$ intervals between 80 and $100{ }^{\circ} \mathrm{C}$ in toluene- $d_{8}$, to determine both the first order rate coefficients for conformational switching and the activation energy. Example data showing the conversion for $\mathbf{1}_{1,3}$ are given in Figure 5 and Table 1. Full data for all compounds and al temperatures are provided in Supporting Information (S15-S18).

For both $\mathbf{1}_{\mathbf{1}, \mathbf{2}}$ and $\mathbf{1}_{\mathbf{1}, \mathbf{3}}$, rather than an equilibrium being established, a simple unidirectional switching mechanism is apparent and there is no evidence for back conversion of the partial cone or further conversion to another conformer from the partial cone.

The results clearly show that the rate of conversion of the 1,2-alternate conformer $\mathbf{1}_{1,2}$ to $\mathbf{1}_{\mathrm{p}}$ is significantly faster ( $k=$ $\left.3.275 \times 10^{-4} \mathrm{~s}^{-1}\right)$ than that for the 1,3-alternate conformer $\mathbf{1}_{1,3}(k=$ $\left.1.415 \times 10^{-4} \mathrm{~s}^{-1}\right)$. However, it should be noted that the activation energy for both processes is comparable, pointing towards entropic factors leading to the differences in rates (Table 1).

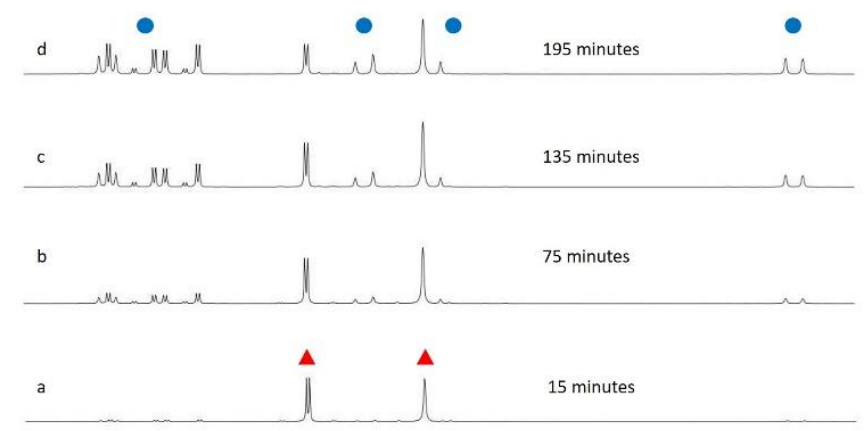

$\begin{array}{llllllllllllllllll}4.6 & 4.5 & 4.4 & 4.3 & 4.2 & 4.1 & 4.0 & 3.9 & 3.8 & 3.7 & 3.6 & 3.5 & 3.4 & 3.3 & 3.2 & 3.1 & 3.0\end{array}$ Figure 5. Representative partial ${ }^{1} \mathrm{H}$ NMR spectra showing conversion of $\mathbf{1}_{\mathbf{1}, 3}$ to $\mathbf{1}_{\mathrm{p}}$ in toluene- $d_{8}$ at $85{ }^{\circ} \mathrm{C}$ a) 15 minutes, b) 75 minutes, c) 135 minutes, d) 195 minutes (Red triangles $\mathbf{1}_{\mathbf{1}, \mathbf{3}}$, Blue circles $\mathbf{1}_{\mathrm{p}}$ )

These data indicate that in the case of the propynyl functionalised calix[4]arenes, the conformational mobility is intermediate between calix[4]arenes functionalised with ethyl groups and those with propyl groups. Whilst the propyl functionalized calix[4]arenes retain fixed conformations, in the case of the ethyl derivatives, more flexibility is shown and it is possible to flip the cone conformation to the partial cone conformation in refluxing THF, an event not seen with $\mathbf{1}_{1,2}$ or $\mathbf{1}_{\mathbf{1}, 3}$. Interestingly, conformational flexibility of a monopropargylated 
derivative of $t$-butyl calix[4]arene has also been reported recently. ${ }^{39}$ Here, the presence of three larger $\mathrm{N}, \mathrm{N}$ dimethylcarbamoylmethoxy groups restrict the rotation to a single aromatic moiety. In this case, a very slow interconversion and development of an equilibrium between a partial cone and a 1,2alternate conformation were observed at room temperature over many months.

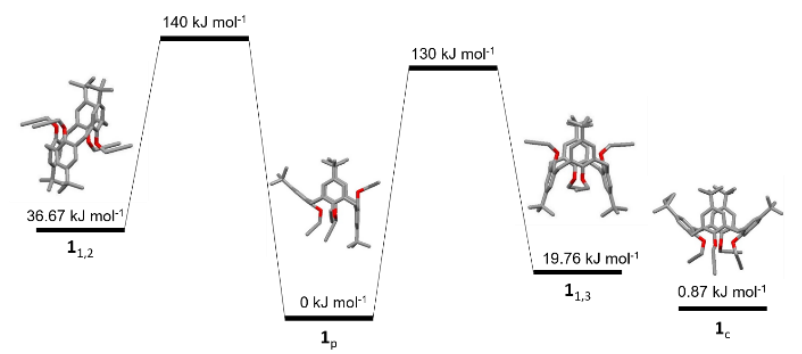

Figure 6. Relative energies of the optimised $a b$ initio structures and transition states to conformation $\mathbf{1}_{\mathbf{p}}$ (not to scale)

Table 1. Experimental first order rate coefficients ${ }^{40}$ and activation energies of the conversion at $85^{\circ} \mathrm{C}$ in toluene- $d_{8}$ (unless otherwise indicated).

\begin{tabular}{lcc}
\hline Conformation & $\begin{array}{c}\text { First order rate } \\
\text { coefficient } k \times 10^{4} / \mathrm{s}^{-1}\end{array}$ & $\begin{array}{l}\text { Activation energy } \\
E_{\mathrm{a}} / \mathrm{kJ} \mathrm{mol}^{-1}\end{array}$ \\
\hline $\mathbf{1}_{\mathbf{1 , 2}}$ & $3.275(53)^{[\mathrm{a}]}$ & $103.2(20)$ \\
$\mathbf{1}_{\mathbf{1 , 3}}$ & $1.415(58)$ & $110.33(81)$ \\
$\mathbf{1}_{\mathbf{1 , 3}}^{[\mathrm{b}]}$ & $0.492(30)$ & $105.4(72)$ \\
$\mathbf{5}_{1,3}$ & $1.069(52)$ & $105.3(45)$ \\
$\mathbf{6}_{\mathbf{1 , 3}}$ & $2.421(28)$ & $133.6(18)$ \\
$\mathbf{6}_{1, \mathbf{2}}$ & $8.38(38)$ & $107.7(76)$
\end{tabular}

[a] Uncertainty given in brackets quoted in units of the last decimal place. [b] Measurements made in DMSO- $d_{6}$

Upper-rim substituent: In order to understand this phenomenon further, the effect of the upper-rim substituent was also considered. Although the 'oxygen through the annulus' mechanism ${ }^{1-3}$ is well established for conformational interconversion of calix[4]arenes, the substituent at the upper-rim has previously been shown to affect conformer distribution significantly. For example, in calix[4]arenes exhibiting dynamic equilibrium the alternate conformations are not observed for ethyl substituted calix[4]arenes in contrast to the $t$-butyl calix[4]arene derivatives. ${ }^{21}$ For our system, the effect of upper-rim substitution on the rate of conformational switching was investigated through an evaluation of both the 1,3-alternate conformations of calix[4]arene $\mathbf{6}_{1,3}$ and $t$-octyl calix[4]arene $\mathbf{5}_{\mathbf{1}, 3}$. Introducing the bulkier group, as in $\mathbf{5}_{\mathbf{1 , 3}}$, results in slower conversion to $\mathbf{5}_{\mathrm{p}}$ which can be attributed to increased 'drag' as the rings rotate, although the rate is not substantially different than that for $\mathbf{1}_{1,3}$ (Table 1 ) suggesting that the system will still switch with extensive upper rim substitution.

However, replacing the $t$-butyl group with a hydrogen, as in $\mathbf{6}_{1,3}$, results in a much faster conversion $\left(k=2.421 \times 10^{-4} \mathrm{~s}^{-1}\right)$ to the partial cone conformation $\mathbf{6}_{\mathrm{p}}$. Importantly, whilst switching was rapid for $\mathbf{6}_{1,3}$, again no conversion of the partial cone conformations $\mathbf{5}_{\mathrm{p}}$ or $\mathbf{6}_{\mathrm{p}}$ to other conformations was observed on heating for over 45 hours at $80^{\circ} \mathrm{C}$ in toluene- $d_{8}$ (Figure S13, S14).

Given these results, combined with the faster conversion of $\mathbf{1}_{1,2}$ than $\mathbf{1}_{\mathbf{1}, 3}$, it is not unexpected that $\mathbf{6}_{1,2}$, the calix[4]arene tetraalkenyl compound in the 1,2-alternate conformation converts the most rapidly on heating in toluene- $d_{8}\left(k=8.38 \times 10^{-4} \mathrm{~s}^{-1}\right)$ with extensive conversion occurring even after 15 minutes at $60^{\circ} \mathrm{C}$.

Solvent effects: The role of solvent on the rate of conversion was also considered. Heating of $\mathbf{1}_{\mathbf{1}, 3}$ in DMSO- $\boldsymbol{d}_{6}$ resulted in conversion to $\mathbf{1}_{\mathbf{p}}$ however the rate of conversion was considerably slower than in toluene (Figures S19-20) and slower than when a more bulky upper-rim substituent is in place. Thus the switch can be tailored both by structure and by solvent.

Ambient Temperature: The possibility of conversion also occurring at ambient temperature was investigated for $\mathbf{1}_{\mathbf{1}, 2}, \mathbf{1}_{\mathbf{1}, \mathbf{3}}$, $\mathbf{6}_{1,3}$ and $\mathbf{6}_{1,2}$. As expected for the 1,2-alternate conformation $\mathbf{6}_{1,2}$ rapid conversion was observed, with significant quantities of $\mathbf{6}_{p}$ produced within hours and full conversion taking place within 9 weeks in a $\mathrm{CDCl}_{3}$ solution (Figure 7 and Table 2). For $\mathbf{1}_{1,2}$ with the larger upper-rim substituent, conversion was slower although more than $50 \%$ conversion was observed over 9 weeks. These observations may help to explain why it is difficult to obtain high yields of $\mathbf{1}_{\mathbf{1}, 2}$ and $\mathbf{6}_{1,2}$ under the published synthetic conditions.

Interestingly, the order of rates of conversion in $\mathrm{CDCl}_{3}$ at ambient temperature is not consistent with those seen in toluene$d_{8}$ at elevated temperatures. The 1,3-alternate conformation $\mathbf{6}_{1,3}$, without an upper-rim substituent is converted more rapidly ( $k=$ $\left.6.89 \times 10^{-7} \mathrm{~s}^{-1}\right)$ than $1_{1,2}\left(k=3.03 \times 10^{-7} \mathrm{~s}^{-1}\right)$ in the 1,2 alternate conformation. In contrast $\mathbf{1}_{\mathbf{1}, 3}$ converts most slowly under these conditions although the presence of $\mathbf{1}_{\mathrm{p}}$ is apparent within 1 week of storage in $\mathrm{CDCl}_{3}$ (Figure S28).

Solvent related effects can also be observed at ambient temperature. Storage of $\mathbf{6}_{1,2}$ in either toluene- $d_{8}$ or DMSO- $d_{6}$ results in a slower conversion to $\mathbf{6}_{\mathrm{p}}$ (Table 2, Figure S32). The results cannot be directly correlated with either dipole moment or viscosity of the solvents and it is likely that a combination of effects is occurring. 


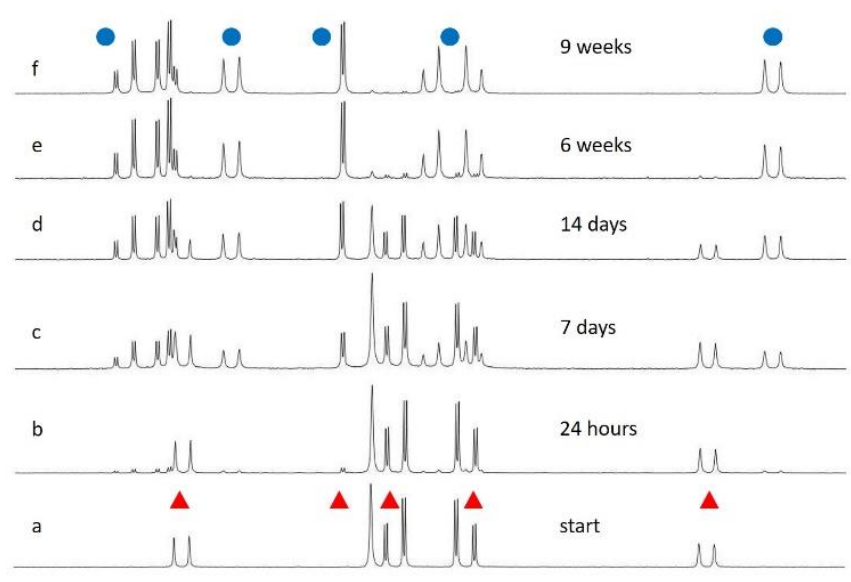

$\begin{array}{lllllllllllllllllllll}7.8 & 4.7 & 4.6 & 4.5 & 4.4 & 4.3 & 4.2 & 4.1 & 4.0 & 3.9 & 3.8 & 3.7 & 3.6 & 3.5 & 3.4 & 3.3 & 3.2 & 3.1 & 3.0\end{array}$

Figure 7. Conversion of $\mathbf{6}_{1,2}$ at ambient temperature in $\mathrm{CDCl}_{3}$. Partial ${ }^{1} \mathrm{H}$ MMR of methylene regions at a) 0 minutes, b) 24 hours, c) 7 days, d) 14 days, e) 6 weeks, f) 9 weeks. (Red triangles $\mathbf{6}_{1,2}$, Blue circles $\mathbf{6}_{\mathrm{p}}$ )

Table 2. First order rate coefficients of the conversion at ambient temperature in $\mathrm{CDCl}_{3}$ (unless otherwise indicated).

\begin{tabular}{lc}
\hline Conformation & First order rate coefficient $k \times 10^{7} / \mathrm{s}^{-1}$ \\
\hline $\mathbf{1}_{1,2}$ & $3.03^{[\mathrm{a}]}$ \\
$\mathbf{1}_{1,3}$ & 1.50 \\
$\mathbf{6}_{1,3}$ & 6.89 \\
$\mathbf{6}_{1,2}$ & 42.8 \\
$\mathbf{6}_{1,2^{[b]}}$ & 25.6 \\
$\mathbf{6}_{1,2}{ }^{[c]}$ & 21.4 \\
{$[$ a] Fractional uncertainty estimated to be $10 \%$. [b] Measurements made in } \\
toluene- $d_{8}[\mathrm{c}]$ Measurements made in DMSO- $d_{6}$
\end{tabular}

Solid State: Recently, Dehaen and Dobrzańska ${ }^{38}$ reported an unprecedented conformational change of a homodithiacalixarene within a single crystal from a 1,3-alternate to a 1,2-alternate conformation in response to release of solvent on heating. The possibility of conversion in the solid state was also investigated for $\mathbf{1}_{1,2}, \mathbf{1}_{1,3}, \mathbf{6}_{1,3}$ and $\mathbf{6}_{1,2}$. Whilst both $\mathbf{1}_{1,3}$ and $\mathbf{6}_{1,3}$ showed no conversion over 7 days when heated as a solid at $100^{\circ} \mathrm{C}$, the 1,2 alternate comformations $\mathbf{1}_{\mathbf{1}, 2}$ and $\mathbf{6}_{1,2}$ gave contrasting results.

For $\mathbf{1}_{\mathbf{1}, 2}$, within the first hour a transformation from crystalline to an amorphous state was observed and an amorphous solid was formed that showed the presence of both the 1,2-alternate $\mathbf{1}_{1,2}$ and partial cone $\mathbf{1}_{\mathrm{p}}$ conformations. Complete conversion to the partial cone $1_{p}$ took place within 12 hours $\left(k=5.69 \times 10^{-5} \mathrm{~s}^{-1}\right)$ (Figure S33). With $\mathbf{6}_{1,2}$ the material appeared to retain its crystaline apperance throughout the study and a slower transformation to $\mathbf{6}_{\mathrm{p}}$ occurred over a period of 7 days (82\% conversion, $k=1.40 \times 10^{-5} \mathrm{~s}^{-1}$ ) (Figure S34). Thus uni-directional switching is possible for the 1,2-alternate conformations even in the solid state.

Table 3. First order rate coefficients of the conversion at $100^{\circ} \mathrm{C}$ in bulk

\begin{tabular}{lc}
\hline Conformation & First order rate coefficient $k \times 10^{5} / \mathrm{s}^{-1}$ \\
\hline $\mathbf{1}_{\mathbf{1}, \mathbf{2}}$ & $5.69^{[\mathrm{a}]}$ \\
$\mathbf{6}_{\mathbf{1 , 2}}$ & 1.40
\end{tabular}

[a] Fractional uncertainty estimated to be $10 \%$.

$\boldsymbol{A b}$ initito calculations: Experimentally, both of the alternate conformations of p-t-butyl calix[4]arene tetraalkyne $\mathbf{1}_{1,2}$ and $\mathbf{1}_{1,3}$ are prone to isomerisation, but the partial cone $\mathbf{1}_{\mathrm{p}}$ and cone $\mathbf{1}_{\mathrm{c}}$ conformations are not. It is not possible from the above experimental data to determine the thermodynamic global minimum and thus the most stable conformer, but it can be suggested this may be in line with results for the methyl and ethyl calixarene derivatives and be the partial cone conformation with the cone conformation inhabiting a thermodynamic local minimum. ${ }^{21}$

This postulate was investigated using density functional theory (DFT) analysis. Optimization of the molecular geometries of the four conformations of $\mathbf{1}$ were performed on the Cartesian co-ordinates ${ }^{41}$ using standard energy minimization techniques as implemented in Gaussian03, ${ }^{42}$ with the B3LYP functional in conjunction with the $6-31 \mathrm{G}(\mathrm{d})$ basis set. All of the optimized geometries were fully characterized and all the vibrational frequencies calculated. The energy calculations (Figure 8, Table 4) reveal that each of the conformations corresponds to a genuine minimum of the potential energy surface. The results confirm that the cone and partial cone conformations are both low energy with the partial cone being the more conformationally stable. In contrast both the 1,3-alternate and 1,2-alternate conformations are high energy and, in line with the experimental data, the least stable conformation is that of the 1,2-alternate.

Table 4. Relative stability of the conformations of 1

\begin{tabular}{llll}
\hline & Energy / Ha & $E_{\text {rel }} / \mathrm{Ha}$ & $E_{\text {rel }} / \mathrm{kJ} \mathrm{mol}^{-1}$ \\
\hline $\mathbf{1}_{\mathbf{c}}$ & -2472.4620794 & 0.000332 & 0.87 \\
$\mathbf{1}_{\mathbf{p}}$ & -2472.4624118 & 0 & 0 \\
$\mathbf{1}_{1.2}$ & -2472.4484469 & 0.013965 & 36.67 \\
$\mathbf{1}_{1,3}$ & -2472.454857 & 0.007525 & 19.76
\end{tabular}


Lower-rim substitution: With these results in hand, we turned our attention to another situation; the conformational stability of the 1,3-alternate conformation of tetrapropenyl calix[4]arene $\mathbf{7}_{1,3}$. This material can be considered to be a useful comparitor between the switchable propynyl and the conformationally locked propyl materials. Heating of 71,3 in toluene- $d_{8}$ at $80^{\circ} \mathrm{C}$ resulted in a considerably slower conformational change (Figure S35) than that seen for $\mathbf{1}_{\mathbf{1}, 3}$, however, over a period of monitoring for 2 days at this elevated temperature, partial transformation into the partial cone conformation $7_{\mathrm{p}}$ was observed,
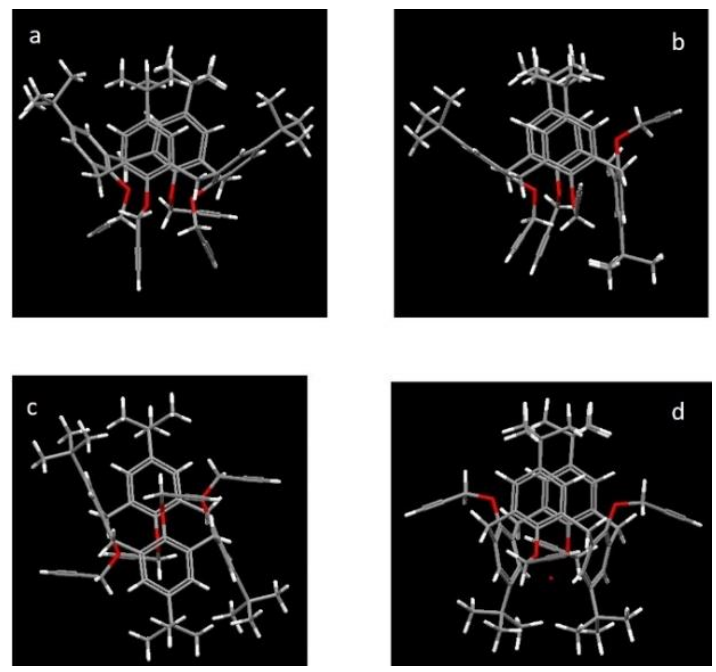

Figure 8. Optimised structures for a) cone conformation $\mathbf{1}_{c}$, b) partial cone conformation $\mathbf{1}_{\mathrm{p}}$. c) 1,2-alternate conformation $\mathbf{1}_{\mathbf{1}, 2}$ d) 1 ,3-alternate conformation $1_{1,3}$

The results observed for both the propynyl and propenyl functionalised calixarenes indicate that neither can be considered to be conformationally fixed. However for $\mathbf{7}$, the interconversion is unlikely to be significant in any experimental applications.

Effect on synthesis: Since the introduction of copper accelerated Huisgen ${ }^{43}$ azide-alkyne cycloadditions (CuAAC) by Meldal ${ }^{44}$ and Sharpless, ${ }^{45}$ there has been considerable interest in alkyne and azide functionalised calix[4]arenes for the formation of sensors ${ }^{46}$ and biologically active calix[4]arenes. ${ }^{47}$

Given the extensive use of these derivatives in synthesis and the previous reports that the partial cone conformation of hexahomotrioxacalix[3]arene ${ }^{48}$ is fully converted to the cone conformation during a click reaction, it was interesting to determine whether the conformational switching could influence CUAAC click chemistry reactions. A series of model reactions between $\mathbf{1}_{\mathbf{1}, 3}$ and benzyl azide were undertaken and product formation monitored over time (Scheme 3).

In the case of standard Huisgen conditions ${ }^{10}$ in the absence of a catalyst, no reaction was observed over the $4 \mathrm{hr}$ period of heating and instead thermal interconversion occurred (Figure S39). However, in the presence of Cul, whether the reaction was

undertaken with thermal or microwave heating, the click reaction was faster than the interconversion and only the 1,3-alternate product could be identified (Figure S38). This indicates that the observed conformational switching is unlikley to be problematic in synthetic applications.

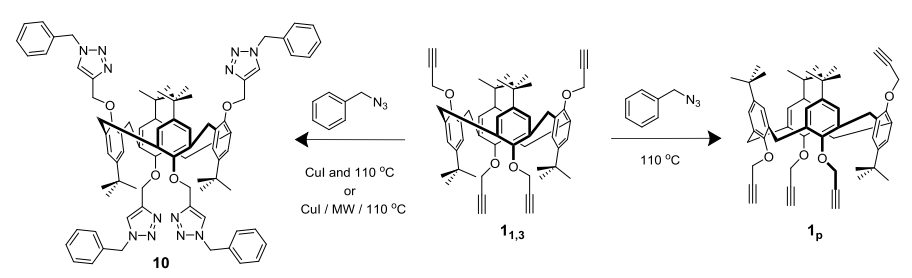

Scheme 3. Effect of conformational interconversion on synthesis

\section{Conclusions}

Here we report the unexpected conformational flexibility of tetrapropynyl calix[4]arene which provides a unique switching system in which two conformations are stable (the cone and partial cone) and two flexible (the 1,2-alternate and 1,3-alternate) within normal operating conditions. Thus the molecule holds an intermediate position between fully flexible ethyl and fully fixed propyl derivatives (Figure 9).

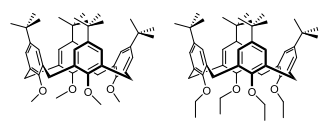

mobile at room mobile above $100^{\circ} \mathrm{C}$ temperature

$$
\begin{array}{cc}
1,3 \text { to } p \text { (ambient and } \\
\text { elevated temperature) } \\
1,2 \text { to } p \text { (ambient and } \\
\text { elevated temperature } \\
\text { and solid state) }
\end{array}
$$

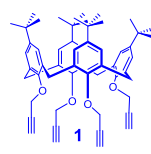

no switching of $c$ and $p$
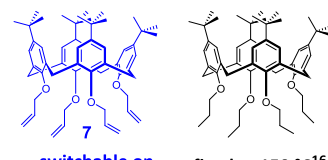

fixed at $150^{\circ} \mathrm{C}^{16}$ prolonged heating

1,3 to $p$ 1,2 to $p$ no switching of $c$ and $p$

Figure 9. Summary of conformational flexibility of tetrafunctionalised calix[4]arenes

The switches are uni-directional from the flexible to stable conformations and the rates of conversion can be tuned by temperature and solvent. The system can be further tailored by alteration of upper-rim and lower-rim substituents and by choice of 1,2-alternate or 1,3-alternate conformations. Additionally, for the 1,2-alternate conformations, conformational conversion is observed in the bulk solid state both in amorphous and crystalline forms.

This new family of switches can be readily synthesized from commercial starting materials in short synthetic sequences and are amenable to further synthetic modification for the introduction of reporter systems and thus offer a new building block which can be exploited for the development of sensors and stimulus responsive materials. 


\section{Experimental Section}

Compounds $\mathbf{1}_{c},{ }^{30} \mathbf{1}_{\mathbf{p}},{ }^{31} \mathbf{1}_{\mathbf{1}, 3},{ }^{31} \mathbf{2},{ }^{31} \mathbf{4},{ }^{33} \mathbf{6}_{\mathrm{p}},{ }^{33} \mathbf{6}_{\mathbf{1}, 3},{ }^{33} \mathbf{7}_{\mathbf{p}},{ }^{34} \mathbf{7}_{\mathbf{1}, 3},{ }^{35}$ and $\mathbf{9}^{49}$ were prepared according to literature procedures. Full experimental details for kinetics experiments and X-ray crystallography are given in Supporting Information.

\section{5,11,17,23-Tetra-p-t-Octyl-25,27-dipropargyloxy-26,28-dihydroxy- calix[4]arene (3)}

A suspension of $p$-t-octyl calix[4]arene ${ }^{50}(3.00 \mathrm{~g}, 3.44 \mathrm{mmol})$ and $\mathrm{K}_{2} \mathrm{CO}_{3}$ $(1.04 \mathrm{~g}, 7.54 \mathrm{mmol})$ was heated at reflux for $1 \mathrm{~h}$ in acetone $(100 \mathrm{~mL})$. Propargyl bromide ( $80 \%$ in toluene, $0.91 \mathrm{~g}, 7.65 \mathrm{mmol}$ ) was added and the mixture heated at reflux for $18 \mathrm{~h}$. The reaction mixture was cooled and filtered. The filtrate was evaporated and the residue re-crystallised from dichloromethane/methanol to yield the title compound $(2.50 \mathrm{~g}, 77 \%)$

Mp 131-133 ${ }^{\circ} \mathrm{C}^{1} \mathrm{H}$ NMR $\delta 7.03(4 \mathrm{H}, \mathrm{s}, \mathrm{Ar}), 6.93(2 \mathrm{H}, \mathrm{s}, \mathrm{OH}), 6.81(4 \mathrm{H}, \mathrm{s}$ $\mathrm{Ar}), 4.74\left(4 \mathrm{H}, \mathrm{d} \mathrm{J}=2.4 \mathrm{~Hz}\right.$, Alkyne), $4.37\left(4 \mathrm{H}, \mathrm{d} \mathrm{J}=13 \mathrm{~Hz}, \mathrm{ArCH}_{2} \mathrm{Ar}\right), 3.34$ $\left(4 \mathrm{H}, \mathrm{d} J=13 \mathrm{~Hz}, \mathrm{ArCH}_{2} \mathrm{Ar}\right), 2.50(2 \mathrm{H}, \mathrm{t} \mathrm{J}=2.4 \mathrm{~Hz}$, Alkyne $), 1.56(4 \mathrm{H}, \mathrm{s}$, $\left.\mathrm{CH}_{2}\right), 1.36\left(4 \mathrm{H}, \mathrm{s}, \mathrm{CH}_{2}\right), 1.34\left(12 \mathrm{H}, \mathrm{s}, \mathrm{CH}_{3}\right), 1.06\left(12 \mathrm{H}, \mathrm{s}, \mathrm{CH}_{3}\right), 0.75(18 \mathrm{H}$, $\left.\mathrm{s}, \mathrm{CH}_{3}\right), 0.27\left(18 \mathrm{H}, \mathrm{s}, \mathrm{CH}_{3}\right){ }^{13} \mathrm{C}$ NMR $\delta 31.1,31.3,31.9,32.19,32.23,32.6$ $32.7,37.9,57.3,57.7,63.5,76.4,78.8,126.2,126.8,127.5,132.6,140.0$ $140.6,146.1,149.2,150.6$. IR $v=3400,3310,2951,2896,2862,1739$ 1600, 1476, 1363,1328, 1283, 1213, $1196 \mathrm{~cm}^{-1}$ ESI MS $966.7332 \mathrm{~m} / \mathrm{z}$ $\left[\mathrm{M}+\mathrm{NH}_{4}\right]^{+}$calcd 966.7334

\section{5,11,17,23-Tetra-p-t-Octyl-25,26,27,28-tetrapropargyloxycalix[4]-} arene (1,3-alternate conformation $5_{1,3}$ ), (partial cone conformation $5_{p}$ ) A suspension of 5,11,17,23-p-t-octyl-25,27-dipropargyloxy-26,28-dihydroxycalix[4]arene $3(1.896 \mathrm{~g}, 2 \mathrm{mmol})$ and caesium carbonate $(1.06 \mathrm{~g})$ was heated at reflux for $1 \mathrm{~h}$ in acetone $(135 \mathrm{~mL})$. Propargyl bromide $(80 \%$ in toluene, $0.74 \mathrm{~g}, 6.22 \mathrm{mmol}$ ) was added and the mixture heated at reflux for $96 \mathrm{~h}$. The reaction mixture was cooled and filtered. The filtrate was evaporated and the residue subjected to column chromatography (hexane/ dichloromethane $3: 1$ ) to yield the tetrasubstituted material as the 1,3 alternate conformation $(0.5 \mathrm{~g})$ and the partial cone conformation $(1.01 \mathrm{~g})$ 1,3-alternate $\left(5_{1,3}\right)$

Mp 25-127 ${ }^{\circ} \mathrm{C}{ }^{1} \mathrm{H}$ NMR $\delta 7.05(8 \mathrm{H}, \mathrm{s}, \mathrm{Ar}), 3.85\left(8 \mathrm{H}, \mathrm{s}, \mathrm{ArCH} \mathrm{CHr}_{2}\right), 3.64(8 \mathrm{H}$ d J = 2.4 Hz, Alkyne), $2.24\left(4 \mathrm{H}, \mathrm{t} \mathrm{J}=2.4 \mathrm{~Hz}\right.$, Alkyne), $1.48\left(8 \mathrm{H}, \mathrm{s}, \mathrm{CH}_{2}\right)$, $1.29\left(24 \mathrm{H}, \mathrm{s}, \mathrm{CH}_{3}\right), 0.68\left(36 \mathrm{H}, \mathrm{s}, \mathrm{CH}_{3}\right){ }^{13} \mathrm{C}$ NMR $\delta 31.4,32.0,32.6,57.6$ 58.4, 74.4, 81.3, 127.9, 134.2, 144.5, 153.1 IR $v=3316,3282,2952,2901$ $1594,1473,1362,1197,1152,1112 \mathrm{~cm}^{-1}$ ESI MS $1042.7645 \mathrm{~m} / \mathrm{z}\left[\mathrm{M}+\mathrm{NH}_{4}\right]^{+}$ calcd 1042.7647 .

\section{Partial cone (5p)}

Mp 160-162 ${ }^{\circ} \mathrm{C}{ }^{1} \mathbf{H}$ NMR $\delta 7.30(2 \mathrm{H}, \mathrm{s}, \mathrm{Ar}), 6.99(2 \mathrm{H}, \mathrm{s}, \mathrm{Ar}), 6.93(2 \mathrm{H}, \mathrm{d} \mathrm{J}$ $=2.3 \mathrm{~Hz}, \mathrm{Ar}), 6.49(2 \mathrm{H}, \mathrm{d} \mathrm{J}=2.3 \mathrm{~Hz}, \mathrm{Ar}), 4.41(4 \mathrm{H}, \mathrm{d} J=2.4 \mathrm{~Hz}$, Alkyne) $4.30(2 \mathrm{H}, \mathrm{d} J=14 \mathrm{~Hz}, \mathrm{ArCH} 2 \mathrm{Ar}), 4.16(2 \mathrm{H}, \mathrm{d} J=2.4 \mathrm{~Hz}$, Alkyne), $3.99(2 \mathrm{H}$ $\mathrm{d} J=2.4 \mathrm{~Hz}$, Alkyne), $3.81(2 \mathrm{H}, \mathrm{d} J=14 \mathrm{~Hz}, \operatorname{ArCH} 2 \mathrm{Ar}), 3.70(2 \mathrm{H}, \mathrm{d} \mathrm{J}=14$ $\left.\mathrm{Hz}, \mathrm{ArCH}_{2} \mathrm{Ar}\right), 3.05\left(2 \mathrm{H}, \mathrm{d} \mathrm{J}=14 \mathrm{~Hz}, \mathrm{ArCH}_{2} \mathrm{Ar}\right), 2.39(2 \mathrm{H}, \mathrm{t} \mathrm{J}=2.4 \mathrm{~Hz}$ Alkyne), $2.33(1 \mathrm{H}, \mathrm{t} \mathrm{J}=2.4 \mathrm{~Hz}$, Alkyne), $2.14(1 \mathrm{H}, \mathrm{t} \mathrm{J}=2.4 \mathrm{~Hz}$, Alkyne) $1.74\left(4 \mathrm{H}, \mathrm{d} J=11 \mathrm{~Hz}, \mathrm{CH}_{2}\right), 1.48\left(6 \mathrm{H}, \mathrm{s}, \mathrm{CH}_{3}\right), 1.44\left(4 \mathrm{H}, \mathrm{d} \mathrm{J}=11 \mathrm{~Hz}, \mathrm{CH}_{2}\right)$, $1.32\left(6 \mathrm{H}, \mathrm{s}, \mathrm{CH}_{3}\right), 1.17\left(6 \mathrm{H}, \mathrm{s}, \mathrm{CH}_{3}\right), 0.97\left(6 \mathrm{H}, \mathrm{s}, \mathrm{CH}_{3}\right) 0.83\left(9 \mathrm{H}, \mathrm{s}, \mathrm{CH}_{3}\right)$, $0.72\left(9 \mathrm{H}, \mathrm{s}, \mathrm{CH}_{3}\right), 0.62\left(18 \mathrm{H}, \mathrm{s}, \mathrm{CH}_{3}\right){ }^{13} \mathrm{C}$ NMR $\delta 31.0,31.4,31.9,32.1$ $32.2,32.3,33.1,38.0,38.1,38.3,57.2,57.3,57.9,58.7,59.1,60.9,73.7$, $74.4,74.64,80.6,81.3,82.2,126.3,126.9,127.1,129.1,132.0,132.6$, 133.0, 136.1, 144.0, 144.4, 151.9, 153.4, 154.0 IR $v=3417,3305,2951$, 2896, 1737, 1594, 1474, 1363, 1198, 1152, $1111 \mathrm{~cm}^{-1}$ ESI MS 1042.7643 $\mathrm{m} / \mathrm{z}\left[\mathrm{M}+\mathrm{NH}_{4}\right]^{+}$calcd 1042.7647

\section{5,11,17,23-Tetra-p-t-Butyl-25,26-dipropargyloxy-27,28-dihydroxy-} calix[4]arene (8)

Sodium hydride $(3.42 \mathrm{~g}, 135.4 \mathrm{mmol})$ was added to a suspension of $p$-tbutyl calix[4]arene ${ }^{51}(20.00 \mathrm{~g}, 30.9 \mathrm{mmol})$ in DMF $(300 \mathrm{~mL})$ and the mixture was stirred for $30 \mathrm{~min}$. Propargyl bromide (80\% in toluene, $9.68 \mathrm{~g}, 67.8$ $\mathrm{mmol}$ ) was added and the mixture stirred for a further $18 \mathrm{~h}$. Water $(50 \mathrm{~mL})$ was added and the resulting solid collected and dried. Silica gel column chromatography (hexane/dicholoromethane 1:2) gave the desired compound as a white solid (5.29 g, 24\%)

Mp $171-173^{\circ} \mathrm{C}^{1} \mathrm{H}$ NMR $\delta 8.27(2 \mathrm{H}, \mathrm{s}, \mathrm{OH}), 6.95(2 \mathrm{H}, \mathrm{d} \mathrm{J}=2.5 \mathrm{~Hz}, \mathrm{Ar})$ $6.92(2 \mathrm{H}, \mathrm{d} \mathrm{J}=2.5 \mathrm{~Hz}, \mathrm{Ar}), 4.89(2 \mathrm{H} \mathrm{dd} \mathrm{J}=16,2.4 \mathrm{~Hz}$, Alkyne) $4.50(1 \mathrm{H}$ $\left.\mathrm{d} J=13 \mathrm{~Hz}, \mathrm{ArCH}_{2} \mathrm{Ar}\right), 4.44\left(2 \mathrm{H}, \mathrm{d} \mathrm{J}=13 \mathrm{~Hz}, \mathrm{ArCH}_{2} \mathrm{Ar}\right), 4.29(1 \mathrm{H}, \mathrm{d} \mathrm{J}=$ $\left.13 \mathrm{~Hz}, \mathrm{ArCH}_{2} \mathrm{Ar}\right), 3.32\left(3 \mathrm{H}, \mathrm{d} \mathrm{J}=13 \mathrm{~Hz}, \mathrm{ArCH}_{2} \mathrm{Ar}\right), 3.30(1 \mathrm{H}, \mathrm{d} \mathrm{J}=13 \mathrm{~Hz}$ $\left.\mathrm{ArCH}_{2} \mathrm{Ar}\right), 2.60(2 \mathrm{H}, \mathrm{t} \mathrm{J}=2.4 \mathrm{~Hz}$, Alkyne $), 1.16\left(18 \mathrm{H}, \mathrm{s}, \mathrm{CH}_{3}\right), 1.09(18 \mathrm{H}$ $\left.\mathrm{s}, \mathrm{CH}_{3}\right){ }^{13} \mathrm{C}$ NMR $\delta 31.4,31.7,32.5,32.8,32.9,34.1,34.3,62.7,76.2,79.7$ $125.3,125.5,126.2,128.9,132.8,134.1,142.8,147.5,149.1,151.0$. IR V
$=3507,3288,2963,2896,2862,1647,1600,1474,1457,1356,1281$, 1202, 1121, $990 \mathrm{~cm}^{-1}$ ESI MS $742.4832 \mathrm{~m} / \mathrm{z}\left[\mathrm{M}+\mathrm{NH}_{4}\right]^{+}$calcd 742.4830

\section{5,11,17,23-Tetra-p-t-Butyl-25,26,27,28-tetrapropargyloxycalix[4]-} arene

(1,2-alternate conformation $\left.\mathbf{1}_{1,2}\right)$

Potassium trimethylsilanolate $(90 \%, 1.94 \mathrm{~g}, 15.11 \mathrm{mmol})$ was added to a stirred solution of $8(2.19 \mathrm{~g}, 3.02 \mathrm{mmol})$ in THF $(100 \mathrm{~mL})$, the mixture stirred for 30 minutes before addition of propargyl bromide ( $80 \%$ in toluene, $4.32 \mathrm{~g} 30.2 \mathrm{mmol}$ ). The solution was stirred for $48 \mathrm{~h}$ and then poured into $1 \mathrm{M} \mathrm{HCl}$. The compound was extracted with dichloromethane $(2 \times 50 \mathrm{~mL})$, washed with saturated $\mathrm{Na}_{2} \mathrm{SO}_{3}(2 \times 50 \mathrm{~mL})$, dried over $\mathrm{MgSO}_{4}$ and the solvent evaporated under reduced pressure. The residue was purified by silica gel column chromatography (hexane/dichloromethane 2:1) to give the title compound $\mathbf{1}_{1,2}$ as a white solid (1.05 g, 42\%).

Mp 107-109 ${ }^{\circ} \mathrm{C}^{1} \mathrm{H}$ NMR $\delta 7.13(4 \mathrm{H}, \mathrm{d} \mathrm{J}=2.5 \mathrm{~Hz}, \mathrm{Ar}), 7.04(4 \mathrm{H}, \mathrm{d} \mathrm{J}=2.5$ $\mathrm{Hz}, \mathrm{Ar}), 4.36\left(2 \mathrm{H}, \mathrm{d} \mathrm{J}=13 \mathrm{~Hz}, \mathrm{ArCH}_{2} \mathrm{Ar}\right), 3.97\left(6 \mathrm{H}, \mathrm{br}\right.$ s $\mathrm{ArCH}_{2} \mathrm{Ar}+$ Alkyne $\left.\mathrm{CH}_{2}\right) 3.90\left(2 \mathrm{H}, \mathrm{d} J=2.4 \mathrm{~Hz}\right.$, Alkyne $\left.\mathrm{CH}_{2}\right), 3.80(4 \mathrm{H}$, dd $\mathrm{J}=15.6 \mathrm{~Hz}, 2.4$ $\mathrm{Hz}$, Alkyne $\left.\mathrm{CH}_{2}\right) 3.21\left(2 \mathrm{H}, \mathrm{d} \mathrm{J}=13 \mathrm{~Hz}, \mathrm{ArCH}_{2} \mathrm{Ar}\right), 2.30(2 \mathrm{H}, \mathrm{t} \mathrm{J}=2.4 \mathrm{~Hz}$, Alkyne $\mathrm{CH}), 1.28\left(36 \mathrm{H}, \mathrm{s}, \mathrm{CH}_{3}\right)^{13} \mathrm{C}$ NMR $\delta 31.7,34.3,38.2,60.0,74.6$ $81.1,125.7,127.0,132.9,134.9,145.3,152.7$ IR $v=3311,3277,2953$ 2907, 2862, 1600, 1586, 1477, 1460, 1361, 1283, 1186, 1121, $1011 \mathrm{~cm}^{-1}$ ESI MS $818.5139 \mathrm{~m} / \mathrm{z}\left[\mathrm{M}+\mathrm{NH}_{4}\right]^{+}$calcd 818.5143

\section{5,26,27,28-Tetrapropargyloxycalix[4]arene}

\section{(1,2-alternate conformation $6_{1,2}$ )}

Potassium trimethylsilanolate $(90 \%, 2.36 \mathrm{~g}, 18.38 \mathrm{mmol})$ was added to a stirred solution of $\mathbf{9}(2.00 \mathrm{~g}, 4 \mathrm{mmol})$ in THF $(100 \mathrm{~mL})$, the mixture stirred for 30 minutes before addition of propargyl bromide (80\% in toluene, 5.00 $\mathrm{g}, 35.00 \mathrm{mmol})$. The solution was stirred for $48 \mathrm{~h}$ and then poured into $1 \mathrm{M}$ $\mathrm{HCl}$. The compound was extracted with dichloromethane $(2 \times 50 \mathrm{~mL})$, washed with saturated $\mathrm{Na}_{2} \mathrm{SO}_{3}(2 \times 50 \mathrm{~mL})$, dried over $\mathrm{MgSO}_{4}$ and the solvent evaporated under reduced pressure. The residue was purified by column chromatography (hexane/dichloromethane 1:2) to give the title compound $\mathbf{6}_{1,2}$ as a white solid (584 $\left.\mathrm{mg}, 25 \%\right)$.

Mp 132-134 ${ }^{\circ} \mathrm{C}{ }^{1} \mathrm{H}$ NMR $\delta 7.18(4 \mathrm{H}, \mathrm{dd} \mathrm{J}=7.5 \mathrm{~Hz}, 1.5 \mathrm{~Hz}, \mathrm{Ar}), 7.08(4 \mathrm{H}$ $\mathrm{dd} J=7.5 \mathrm{~Hz}, 1.5 \mathrm{~Hz}, \mathrm{Ar}), 6.93(4 \mathrm{H}, \mathrm{t} J=7.5 \mathrm{~Hz}, \mathrm{Ar}), 4.44(2 \mathrm{H}, \mathrm{d} J=13$ $\left.\mathrm{Hz}, \mathrm{ArCH}_{2} \mathrm{Ar}\right), 4.03\left(4 \mathrm{H}\right.$, s $\left.\mathrm{ArCH}_{2} \mathrm{Ar}\right), 3.98(4 \mathrm{H}$, dd J = $15.7 \mathrm{~Hz}, 2.5 \mathrm{~Hz}$, Alkyne $\left.\mathrm{CH}_{2}\right), 3.82\left(4 \mathrm{H}\right.$, dd $\mathrm{J}=15.7 \mathrm{~Hz}, 2.5 \mathrm{~Hz}$, Alkyne $\left.\mathrm{CH}_{2}\right) 3.30(2 \mathrm{H}, \mathrm{d} \mathrm{J}$ $\left.=13 \mathrm{~Hz}, \mathrm{ArCH}_{2} \mathrm{Ar}\right), 2.35(2 \mathrm{H}, \mathrm{t} \mathrm{J}=2.4 \mathrm{~Hz}$, Alkyne $\mathrm{CH}){ }^{13} \mathrm{C}$ NMR $\delta 30.8$, $37.1,59.9,74.6,80.3,123.4,128.7,129.9,133.8,135.9,154.4$ IR $v=3270$, 2919, 1585, 1455, 1361, 1250, 1187, 1090, $1006 \mathrm{~cm}^{-1}$ ESI MS 594.2632 $\mathrm{m} / \mathrm{z}\left[\mathrm{M}+\mathrm{NH}_{4}\right]^{+}$calcd 594.2639.

\section{Acknowledgements}

The authors thank the University of East Anglia, the University Claude Bernard Lyon 1 and the CNRS for financial support. S. C. thanks the Région Rhône-Alpes (Cluster de Recherche Chimie) for additional funding. The authors would like to thank EPSRC UK National Mass Spectrometry Facility at Swansea University for provison of high resolution mass spectral analyses.

Keywords: Calix[4]arene - Conformational Analysis • Molecular Switching $\bullet$ Kinetics $\cdot{ }^{1} \mathrm{H}$ NMR

[1] V. Böhmer Angew. Chem. Int. Ed. Engl. 1995, 34, 713-745.

[2] C. D. Gutsche, Calixarenes Revisited, Monographs in Supramolecular Chemistry, Royal Society of Chemistry, 1998, Cambridge, UK.

[3] C. D. Gutsche, Calixarenes, Monographs in Supramolecular Chemistry, Royal Society of Chemistry, 1989, Cambridge, UK.

[4] For extensive reviews of applications see:

Calixarenes 2001 (Eds. Z. Asfari, V. Böhmer, J. Harrowfield J. Vicens) Kluwer, Dordrecht, Netherlands 2001. Calixarenes in the Nanoworld (Eds. J. Vicens, J. Harrowfield) Springer, Netherlands 2007. Calixarenes and Beyond (Eds. P. Neri, J. L. Sessler, M-X. Wang) Springer, Switzerland 2016. 
[5] V. A. Azov, A. Beeby, M. Cacciarini, A. G. Cheetham, F. Diederich, M. Frei, J. K. Gimzewski, V. Gramlich, B. Hecht, B. Jaun, T. Latychevskaia A. Lieb, Y. Lill, F. Marotti, A. Schlegel, R. R. Schlittler, P. J. Skinner, P. Seiler, Y. Yamakoshi Adv. Funct. Mater. 2006, 16, 147-156.

[6] J. R. Moran, J. L. Ericson, E. Dalcanale, J. A. Bryant, C. B. Knobler, D. J. Cram, J. Am. Chem. Soc., 1991, 113, 5707-5714.

[7] L. D. Shirtcliff, H. Xu, F. Diederich Eur. J. Org. Chem. 2010, 846-855

[8] M. Frei, F. Diederich, R. Tremont, T. Rodriguez, L. Echegoyen Helv. Chim. Acta, 2006, 89, 2040- 2057.

[9] a) P. Amrhein, P. L. Wash, A. Shivanyuk, J. Rebek Org. Lett., 2002, 4 319-321; b) P. Amrhein, A. Shivanyuk, D. W. Johnson, J. Rebek J. Am. Chem. Soc. 2002, 124, 10349-10358; c) M. Frei, F. Marotti, F. Diederich Chem. Commun. 2004, 1362-1363.

[10] a) S. E. Matthews, P. Schmitt, V. Felix, M. G. B. Drew, P. D. Beer, J. Am Chem. Soc., 2002, 124, 1341-1353; b) P. Schmitt, P. D. Beer, M.G. B. Drew, P. D. Sheen Angew. Chem. Int. Ed. Engl. 1997, 36, 1840-1842.

[11] D. S. Kim, J. L. Sessler Chem. Soc. Rev., 2015, 44, 532-546.

[12] L. Adriaenssens, P. Ballester Chem. Soc. Rev., 2013, 42, 3261-76.

[13] a) J. S. Park, K. Y. Yoon, D. S. Kim, V. M. Lynch, C. W. Bielawskia, K. P. Johnston, J. L. Sessler Proc. Nat. Acad. Sci., 2011, 108, 2091320917; b) D. S. Kim, J. Chang, S. Leem, J. S. Park, P. Thordarson, J. L. Sessler J. Am. Chem. Soc. 2015, 137, 16038-16042.

[14] P. Sokkalingam, J. Yoo, H. Hwang, P. H. Lee, Y. M. Jung, C.-H. Lee Eur. J. Org. Chem. 2011, 2911-2915.

[15] D. S. Kim, V. M. Lynch, J. S. Park, J. L. Sessler J. Am. Chem. Soc., 2013 135, 14889-14894.

[16] K. Araki, K. Iwamato, K, S. Shinkai Chem Lett. 1989, 18, 1747-1750.

[17] K. Iwamato, K. Araki, K, S. Shinkai J. Org. Chem. 1991, 56, 4955-4962.

[18] V. Bocchi, D. Foina, A. Pochini, R. Ungao Tetrahedron 1982, 38, 373378.

[19] L. C. Groenen, J-D. van Loon, W. Verboom, S. Harkema, A. Casnati, R. Ungaro, A. Pochini, F. Ugozzoli, D. N. Reinhoudt J. Am. Chem. Soc. 1991, 113, 2385-2392.

[20] C. D. Gutsche, B. Dhawan, J. A. Levine, K. H. No, L. J. Bauer, Tetrahedron 1983, 39, 409- 426.

[21] T. Harada, J. M. Rudzinski, S. Shinkai J. Chem. Soc. Perkin Trans. 2 1992, 2109-2115.

[22] K. Iwamoto, A. Ikeda, K. Araki, T. Harada, S. Shinkai Tetrahedon 1993 49, 9937-9946.

[23] A. Soi, W. Bauer, H. Mauser, C. Moll, F. Hampel, A. Hirsch J. Chem. Soc. Perkin Trans. 2 1998, 1471-1478.

[24] S. Akabori, H. Sannhoe, Y. Habata, Y. Mukoyama, T. Ishii Chem Commun. 1996, 1467-1468.

[25] D. D'Alessio, A. M. Krause-Heuer, B. W. Skelton, B. H. Fraser, M. Massi, M. I. Ogden RSC Adv. 2016, 6, 37006-37011.

[26] K. C. Nam, S. O. Kang, Y. J. Ki Supramol. Chem., 2002, 14, 503-509

[27] K. Araki, H. Shimizu, S. Shinkai, Chem. Lett. 1993, 22, 205-208.

[28] R. Ungaro, A. Casnati, F. Ugozzoli, A. Pochini, J.-F. Dozol, C. Hill, H. Rouquette, Angew. Chem. Int. Ed. Engl. 1994. 33, 1506-1509.

[29] a) T. Pierro, C. Gaeta, P. Neri, Supramol. Chem. 2010, 22, 726-736; b) T. Pierro, C. Gaeta, F. Troisi, P. Neri Tetrahedron Lett. 2009, 50, 350353.

[30] E-H. Ryu, Y. Zhao Org. Lett., 2005, 7, 1035-1037.

[31] S. Cecioni, R. Lalor, B. Blanchard, J-P. Praly, A. Imberty, S. E. Matthews, S. Vidal Chem. Eur. J. 2009, 15, 13232-13240

[32] M. Nieger, I. Michel, F. Vögtle, Private comm. to the CCDC. Ref. code IXEWIR01 for the partial cone conformation.

[33] W. Xu, J. J. Vittal, R. J. Puddephatt, Can. J. Chem., 1996, 74, 766-774.

[34] S. Stumpf, G. Goretzki, K. Gloe, K. Gloe, W. Seichter, E Weber, J. W. Bats J. Incl. Phenom. Macr. Chem. 2003, 45, 225-233.

[35] R. T. Chester, D. Couton, R. Lobler, M. Mocerino, M. I. Ogden, J. K. Pettersen, B. W. Skelton, A. H. White J. Incl. Phenom. Macrocycl. Chem 2011, 71, 471-477.
[36] S. E. Matthews, M. Saadioui, V. Böhmer, S. Barboso, F. Arnaud-Neu, M.-J. Schwing-Weill, A. Garcia Carrera, J.-F. Dozol J. Prakt. Chem. 1999, 341, 264-273.

[37] P. Lhoták, A. Bíla, J. Budka, M. Pojarová, I. Stibor Chem Commun. 2008 1662-1664.

[38] J. Thomas, G. Reekmans, P. Adriaensens, L. Van Meervelt, M. Smet, W Maes, W. Dehaen, L. Dobrzańska Angew. Chem. Int. Ed. 2013, 52, 1023710240.

[39] J. B. Czirok, Á. Tarcsay, P. D. Mezei, A. Simon, L. Balázs I. Bitter Supramol. Chem. 2014, 26, 722-728.

[40] a) P. C. Mangelsdorf J. Appl. Phys. 1959, 30, 442-443; b) E. S. Swinbourne, J. Chem. Res. 1960, 2371-2372.

[41] Cone and 1,3-alternate: M. J. Chetcuti, A. M. J. Devoille, A. Ben Othman, R. Souane, P. Thuery, J. Vicens, Dalton Trans. 2009, 2999-3008. 1,2alternate and partial cone: see crystal structure data in $\mathrm{SI}$

[42] M. J. Frisch, G. W. Trucks, H. B. Schlegel, G. E. Scuseria, M. A. Rob, J. R. Cheeseman, J. A. Montgomery Jr, T. Vreven, K. N. Kudin, J. C. Burant, J. M. Millam, S. S. Iyengar, J. Tomasi, V. Barone, B. Mennuci, M. Cossi, G. Scalmani, N. Rega, G. A. Petersson, H. Nakatsuji, M. Hada, M. Ehara K. Toyota, R. Fukuda, J. Hasegawa, M. Ishida, T. Nakajima, Y. Honda O. Kitao, H. Nakai, M. Klene, X. Li, J. E. Knox, H. P. Hratchian, J. B. Cross, J. Bakken, C. Adamo, J. Jaramillo, R. Gomperts, R. E. Stratmann, O. Yazyev, A. J. Austin, R. Cammi, C. Pomelli, J. W. Ochterski, P. Y Ayala, K. Morokuma, G. A. Voth, P. Salvador, J. J. Dannenberg, V. G. Zakrzewski, S. Dapprich, A. D. Daniels, M. C. Strain, O. Farkas, D. K. Malick, A. D. Rabuck, K. Raghavachari, J. B. Foresman, J. V. Ortiz, C Cui, A. G. Baboul, S. Clifford, J. Cioslowski, B. B. Starfanov, G. Liu, A Liashenko, P. Piskorz, I. Komaromi, R. L. Martin, D. J. Fox, T. Keith, M. A. Al-Laham, C. Y. Peng, A. Nanayakkara, M. Challacombe, P. M. W Gill, B. Johnson, W. Chen, M. W. Wong, C. Gonzalez, J. A. Pople, Gaussian 03 (Gaussian Inc., Wallingford CT 2003)

[43] R. Huisgen, G. Szeimies, L. Mobius Chem. Ber. 1967, 100, 2494-2507.

[44] a) C. W. Tornøe, C. Christensen, M. Meldal J. Org. Chem. 2002, 67, 3057-3064; b) M. Meldal, C. W. Tornoe Chem. Rev. 2008, 108, 29523015.

[45] V. V. Rostovtsev, L. G. Green, V. V. Fokin, K. B. Sharpless, K. B. Angew. Chem. Int. Ed. 2002, 41, 2596-2599.

[46] a) S-Y. Park, J. Yoon, C. S. Hong, R. Souane, J. S. Kim, S. E. Matthews J. Vicens J. Org. Chem. 2008, 73, 8212-8218; b) J. S. Kim, S. Y. Park S. H. Kim, P. Thuéry, R. Souane, S. E. Matthews, J. Vicens Bull. Kor. Chem. Soc. 2010, 31, 624-629

[47] a) A. M. Boukerb, A. Rousset, N. Galanos, J.-B. Méar, M. Thépaut, T. Grandjean, E. Gillon, S. Cecioni, C. Abderrahmen, K. Faure, D. Redelberger, E. Kipnis, R. Dessein, S. Havet, B. Darblade, S. E. Matthews, S. de Bentzmann, B. Guéry, B. Cournoyer, A. Imberty, S. Vidal J. Med. Chem. 2014, 57, 10275-10289; b) A. Dondoni, A. Marra Chem. Rev. 2010, 110, 4949-4977; c) F. Sansone, A. Casnati Chem Soc. Rev. 2013, 42, 4623-4639; d) S. Cecioni, A. Imberty, S. Vidal Chem. Rev. 2015, 115, 525-561.

[48] C.-C. Jin, T. Kinoshita, H. Cong, X.-L. Ni, X. Zeng. D. L. Hughes, C. Redshaw, T. Yamato New. J. Chem., 2012, 36, 2580-2586.

[49] P. Slavik, V. Eigner, P. Lhotak, Tetrahedron, 2016, 72, 6348-6355.

[50] K. Ohto, M. Yano, K. Inoue, T. Yamamoto, M. Goto, F. Nakashio, S. Shinkai, T. Nagasaki, T. Anal. Sci. 1995, 11, 893-902.

[51] C. D. Gutsche, M. Iqbal Org. Synth. 1990, 68, 234-237. 